\title{
Mental capacity, legal competence and consent to treatment
}

\author{
Alec Buchanan PhD MD
}

J R Soc Med 2004;97:415-420

\section{SUMMARY}

Deciding whether someone is legally competent to make decisions regarding their own treatment requires an assessment of their mental capacity. The assessed capacity required for legal competence increases with the seriousness of what is at stake. The usual explanation is that patient autonomy is being balanced against best interests. An alternative explanation, that we require greater room for error when the consequences are serious, implies a change to clinical practice and in the evidence doctors offer in court.

\section{INTRODUCTION}

When a patient refuses medical treatment, the law in the UK, the US, and Canada requires that their stated wishes be respected unless they can be shown not to be legally competent ${ }^{1-9}$. Legal competence is specific to the task at hand. ${ }^{10}$ It requires the mental capacities to reason and deliberate, ${ }^{15,16}$ hold appropriate values and goals, ${ }^{17}$ appreciate one's circumstances, ${ }^{18,19}$ understand information one is given ${ }^{20}$ and communicate a choice. ${ }^{15}$ These capacities can change over time, so medical procedures that require consent over extended periods necessitate repeated assessments. ${ }^{21}$ The law recognizes that mental capacity is a continuous quality that may be present to a greater or lesser extent. 22

Legal competence, however, cannot be present to a greater or lesser extent. A person is either entitled or not entitled, at law, to have their wishes respected regarding treatment. Doctors, patients' relatives and, in contested cases, the courts have to decide, where someone's right to accept or refuse treatment is in doubt, whether that person's mental capacity is sufficient for legal competence and their stated wishes should therefore be respected. Two questions arise. Should the amount of capacity required for legal competence increase in response to the gravity of the decision that the patient faces? And if it should, why?

The question of whether an increase in the gravity of the consequences should produce a corresponding increase in the amount of mental capacity required for legal competence will be discussed in the first part of the paper. The usual conclusion is that it should, with the qualification that the law's approach to patient autonomy complicates the

Division of Law and Psychiatry, Yale University Department of Psychiatry, 34 Park Street, New Haven CT 06519, USA

E-mail: alec.buchanan@yale.edu relationship. The second part of the paper examines the reasons for varying the threshold level of capacity in this way. The third examines two other considerations, relevant to whether someone's wishes regarding their medical care will be respected, which bear on this practice of moving the threshold level of capacity required for legal competence in response to what is at stake.

\section{DOES WHAT IS AT STAKE ALTER THE LEVEL OF CAPACITY NECESSARY FOR LEGAL COMPETENCE?}

The claimant in Re T was a Jehovah's Witness who had been given a blood transfusion when unable to give or refuse consent. The Court of Appeal addressed the question of whether the life-threatening circumstances were relevant to whether the patient's capacity was sufficient for the refusal to be respected. It held that they were:

'What matters is that the doctors should consider whether at that time he had a capacity which was commensurate with the gravity of the decision. The more serious the decision, the greater the capacity required.' 22

Two psychiatrists had assessed the capacity of the claimant in $\operatorname{Re} B$ after she stated that she wished the ventilator, which had kept her alive since she had become tetraplegic, switched off. The High Court of England and Wales noted that 'her mental competence is commensurate with the gravity of the decision she may wish to make.'

Medical and philosophical commentators likewise recognize this proportionality. ${ }^{23-25}$ The application of the principle in most cases, however, does not exclude the possibility that, at some point, it ceases to operate. This point or threshold could be defined in terms of gravity or in 


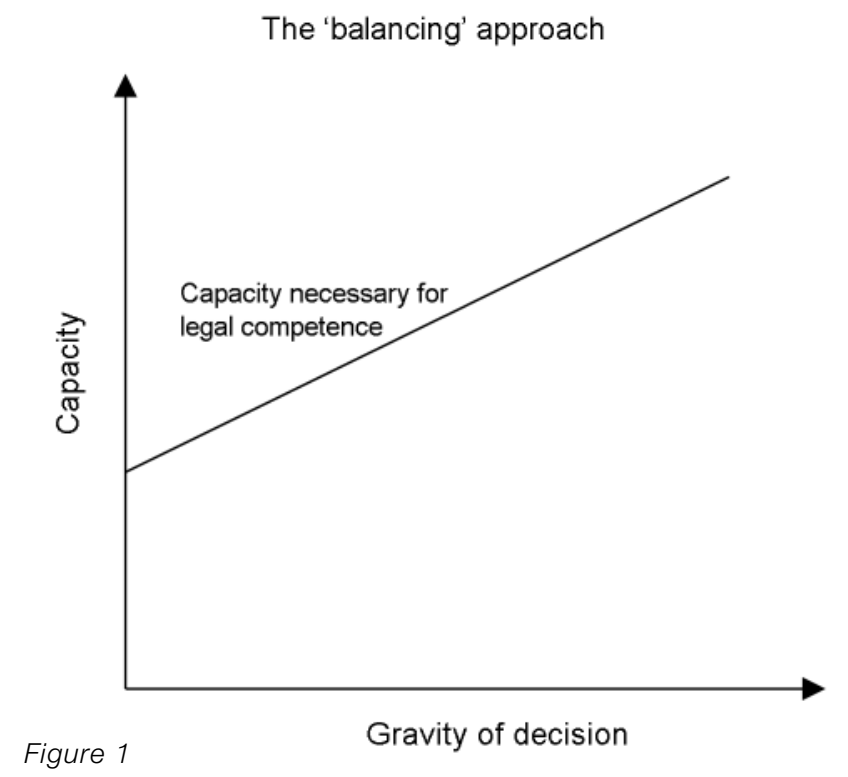

terms of capacity. Medical writers have suggested that, where gravity is extreme, doctors and courts allow their dislike of what a patient proposes to outweigh their desire to see that person's wishes respected, whatever the patient's capacity. ${ }^{26-29}$ Legal writers in Britain detect an inappropriate stretching of the remit of the Mental Health Act - to achieve the same result. ${ }^{30}$

It is possible also, however, that a threshold that limits proportionality will be couched in terms of capacity. Later in its judgment in $\operatorname{Re} B$ the High Court noted:

'If refusal might have grave consequences for the patient, it is most important that those considering the issue should not confuse the question of mental capacity with the nature of the decision made by the patient, however grave the consequences. ${ }^{1}$

The court had undertaken a detailed review of the patient's history and mental condition and concluded that her mental capacities were intact. In these circumstances, the judgment suggests, proportionality ceases to apply. There comes a point when a patient's capacity is such that any decision to refuse treatment should be respected, however serious the consequences. Medical commentators have referred similarly to the need for some impairment of the 'power of autonomous choice' before any treatment can be given or withheld without consent. ${ }^{31}$

If there is a principle that operates to raise the threshold level of mental capacity required for legal competence, therefore, the operation of that principle may be limited at extremes of capacity and gravity. The practical consequences have not been described systematically. Most judgment does not always describe the court's rationale. Empirical research could examine the question by presenting clinicians and jurists with hypothetical cases or by observing what they do in circumstances where there is variation in the severity of what is at stake. In the majority of cases, however, the limits of capacity and gravity are not reached. What principles then govern the practice, described in $\operatorname{Re} T$, whereby the level of capacity required for competence rises in proportion to what is at stake?

\section{THE PRINCIPLES GOVERNING PROPORTIONALITY}

\section{Balancing autonomy and wellbeing}

The rationale offered most frequently is that the good of acting in a patient's best interests always has to be balanced against another good, that of respecting the same patient's autonomy. ${ }^{32}$ Autonomy has been variously defined as free action which authentically reflects an actor's values and beliefs and which results from effective deliberation and reflection ${ }^{33}$ and as acting intentionally, with understanding and in the absence of controlling influences. ${ }^{25}$ According to the 'balancing' justification for proportionality, capacity is either a measure of how much autonomy someone has or a measure of how much value should be attached to respecting that autonomy. ${ }^{34}$ In either case, all other things being equal, the more capacity someone has, the more likely that the benefit of respecting their autonomy will outweigh any cost to their wellbeing. ${ }^{35,36}$

As a result, the threshold level of capacity required for legal competence has to rise as the consequences become more serious (Figure 1). ${ }^{37}$ "When little turns on the decision,' on the other hand, 'the level of decision-making capacity required [for a patient's consent to be regarded as competent] may be appropriately reduced. ${ }^{38}$ Other writers refer to the threshold varying with the seriousness ${ }^{27,36}$ of what is being decided, how much the patient has to $\operatorname{lose}^{36}$ or what is at stake. ${ }^{25}$

Because the consequences of different decisions are different, under the balancing approach the same patient can properly be allowed to decide whether or not to take medication but denied the right to decide whether to undergo a hazardous surgical procedure. ${ }^{27,39}$ Because the consequences of consenting to a procedure are different from those of refusing to undergo it, a person can be competent to refuse to participate in research but not to agree, ${ }^{21}$ and to consent to a treatment but not to refuse. ${ }^{4}$ This aspect of the balancing approach seems to place a peculiar burden on the procedures for seeking consent. Whether or not a treatment decision is to be respected depends on the terms in which the question is couched.

A balancing approach also has to establish what needs to be balanced. Definitions of wellbeing refer to the risks and 
benefits ${ }^{15,26}$ or risk-benefit ratio ${ }^{41,42}$ of what is proposed, the level of capacity required for legal competence rising with the extent to which the risks outweigh the benefits. When the risks and benefits of a course of treatment are thus compared, however, no allowance is made for the fact that in practice there may be other means of obtaining the same benefit. One way in which a balancing approach might take this into account would follow Terry's analysis, whereby the 'reasonableness' of a risk depends on five elements - the probability of harm; the value given to that harm; the probability that the goal which necessitates risking the harm will, in fact, be achieved; the value attributed to that goal; and the 'necessity' of taking the risk, given that alternative strategies may be available to achieve the same goal. ${ }^{43}$

\section{Leaving room for error}

The balancing account also runs contrary to a principle that has been traced to Judaic and Greek history and to Kant. ${ }^{44}$ This principle holds that a person's autonomy is paramount. ${ }^{31,45,46}$ Any balancing against other considerations is, as a result, 'disrespectful' 39 of that autonomy. ${ }^{47}$ If this alternative principle is nevertheless to permit the proportionality described in $\operatorname{Re} T$ it must do so by a different mechanism. The most obvious candidate is our preference for greater certainty before permitting decisions that may lead to great harm.

Any measurement of capacity is subject to error, and any legal judgment that someone is competent to make a decision that is based on a measurement of capacity will be similarly susceptible. In practice, competence is only at issue when a patient decides contrary to what others regard as in their best interests. Two types of error are then

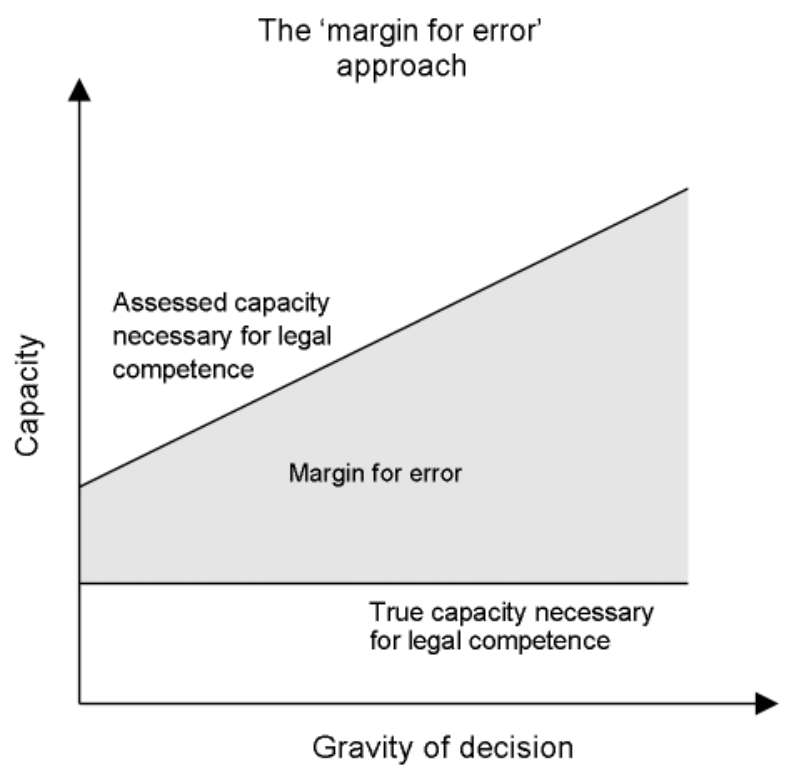

Figure 2 available to courts and clinicians. ${ }^{48}$ An incorrect conclusion that the patient is not competent in these circumstances usually leads to their receiving the treatment that others regard as in their best interests. An incorrect conclusion that the patient is competent usually results in their coming to what others regard as harm.

Raising the threshold level of capacity required for competence when the anticipated harm is greatest stems, by this argument, from a clinician's or a court's wish to be more certain. ${ }^{45,49}$ It means leaving a greater margin for error when the consequences are serious (Figure 2). ${ }^{50,51}$ Raising the threshold, of course, also increases the number of instances in which people are incorrectly assessed as not legally competent. Harm is then being done because their autonomous wishes are not respected. This is a different type of harm from that of failing to act in someone's best interests. Advocates of a 'margin-for-error' approach have to assume that it does not increase in severity in response to what is at stake or, if it does so increase, that it does not do so as much.

The margin-for-error approach seems to have been preferred by the President's Commission for the Study of Ethical Problems in Medicine and Biomedical and Behavioral Research in the US. The Commission's report referred to a 'greater need to be certain that the patient possesses the necessary level of capacity' when the consequences for wellbeing are substantial and concluded:

'A serious disagreement about a decision with substantial consequences ... may appropriately trigger further evaluation. When that process indicates that the patient understands the situation and is capable of reasoning soundly about it, the patient's choice should be accepted. ${ }^{38}$

A desire for greater certainty similarly seems to have motivated the National Bioethics Advisory Commission's call for increased scrutiny (in the form of independent and qualified assessors) of someone's decision to participate in research when the risk is more than negligible. ${ }^{21}$

The implications for clinical practice of leaving room for error seem to be different from those that follow from balancing best interests and autonomy. For example, additional information confirming a previously assessed level of capacity could lead to a patient's being found competent to manage his or her own affairs in circumstances where, in the absence of such additional information, the combination of the gravity of the consequences and uncertainty regarding the patient's competence would have led to that person being judged not competent. In other words the source and level of doubt attaching to any conclusion regarding capacity should form part of any evidence going to legal competence since it will contribute to the subsequent adjudication of that 
competence. The approach has an analogy in medical statistics. Instead of simply a mean, what is being required of doctors is a mean and standard deviation.

\section{OTHER CONSIDERATIONS AFFECTING PROPORTIONALITY}

The degree to which the threshold level of capacity necessary for legal competence varies in proportion to what is at stake is limited, it was suggested in the first section, by the effect of thresholds. There comes a point when someone's capacity is such that the law will regard him or her as legally competent, whatever the consequences. Two other considerations seem further to affect the degree to which the level of capacity required for competence varies in response to what is at stake.

\section{Medical ethics}

The principle of beneficence includes injunctions not to do harm, to prevent evil or harm, to remove evil or harm and to promote good. Not all of these have the same power in an individual case, and the relationship between them is complex. There are times when negative duties-not to injure, for instance-seem to outweigh positive duties to help others; doctors do not consider it justifiable to kill a patient, whatever the prognosis, in order that others may benefit from the transplantation of that patient's organs. ${ }^{39}$ There are other times when a chance of benefit seems more important than a higher chance of doing harm, as when a risky procedure is justified by the prospect, however slim, of a cure.

In any case, factors other than this type of utilitarian calculus influence medical behaviour. Doctors seem to pay more attention to a patient's subjective view of what is best than any objectively derived one, for instance, and beneficence is expected to be aimed primarily at the person whom the doctor is treating. Veatch calls these 'nonconsequentialist' injunctions. ${ }^{52}$ Among them seems to be limiting intrusion as far as is possible. ${ }^{53}$ In Quinlan the New Jersey court reflected that the case for over-ruling a patient's wishes not to be treated weakened 'as the degree of bodily invasion increases'. 54

\section{Parsimony}

Respecting people's stated wishes can be a desirable end even when those wishes are the expression of a legally incompetent choice. The humane running of psychiatric, medical and geriatric units where lack of capacity to make legally binding decisions is commonplace would seem to require a parsimonious approach to coercion. ${ }^{10,19}$ The House of Lords' judgment in Bournewood ${ }^{55}$ that, where a best interests and does not object, no further legal action is necessary, suggests that the courts prefer a similarly parsimonious approach to declaring someone legally incompetent. Wicclair offers the example of a five-yearold child whose parents permit him to choose what he will eat for lunch unless one of the items on the menu is lifethreatening to him. ${ }^{56}$ It is possible, as the balancing and margin-for-error approaches would both allow, that the child is legally competent to make one decision but not the other. It seems more likely, however, that this competence is the same but that his parents wish to respect the child's choices where doing so does not lead to harm.

Erde extends this argument to instances where respecting a legally incompetent choice leads to some harm but where the alternative, going against the person's stated wishes, will do more harm. ${ }^{57}$ One example is the refusal of medication in circumstances where the harm of enforcing compliance exceeds the harm of the patient doing without. More important than these utilitarian considerations, however, may be the fact that a proper respect for the wishes of others is not dependent on their having any particular level of intellectual or emotional capacity. One drawback of the balancing approach to competence, according to Checkland, is that it leaves no room for incompetent wishes that should nevertheless be respected. ${ }^{58,59}$ Whatever it is about a person that leads us to owe them respect, they do not lose it by virtue of becoming legally incompetent.

\section{CONCLUSION}

Mental capacity is not the sole determinant of what will happen when a patient chooses a course of treatment that doctors consider against that patient's best interests. The views of relatives, the previously expressed views of the patient, the opinions of hospital staff and society's values all have a currency. Any attempt rigidly to define a group of legally incompetent people is likely to have adverse consequences for patients and the care they receive. ${ }^{60}$ In Anglo-American law, however, mental capacity has a primacy which is directly relevant in cases which reach the courts and which therefore influences decisions in many which do not. Central to any discussion of mental capacity is whether the quantity required for legal competence should vary with what is at stake for the patient. The question has not been widely addressed beyond the fields of philosophy and medical ethics. ${ }^{23,49}$

The usual conclusion, that the amount of capacity required should vary in proportion to the gravity of the consequences, requires several qualifications. First, the law's treatment of autonomy as paramount limits the application of this proportionality to people with defective capacity. Second, the justification for proportionality most frequently 
offered, whereby autonomy is balanced against wellbeing, does not reflect the status accorded to patient autonomy by the law. An alternative that does reflect this status implies that current practice should change. Third, ethical considerations, and a widely held desire to limit the circumstances in which express wishes are not respected, further limit the degree to which the level of capacity required for legal competence is proportionate to the gravity of the patient's decision.

The complexity of many of these questions may have limited the degree to which they have been addressed. No decision as to whether or not a refusal of treatment should be respected can or should be made by means of a diagram or a formula. Patients, relatives and medical staff make and contribute to decisions regarding care and treatment in circumstances where generalizations are difficult and sometimes impossible to apply. ${ }^{61}$ However, if as the UK's Draft Mental Incapacity Bill suggests, capacity is to assume a greater role in deciding what will happen to patients, ${ }^{10}$ and if the various instruments to measure capacity ${ }^{16,62-65}$ are to have a role beyond description, the nature of the relationship between the capacity required for legal competence and the gravity of the decision which a person faces requires continued attention. Medical and legal reluctance to intervene when a legally incompetent patient accepts treatment runs counter to the Court of Appeal (but not the House of Lords) judgment in Bournewood. ${ }^{66}$ Some will regard as too parsimonious an approach that allows a patient's lack of objection to prevent their capacity being fully assessed and appropriate safeguards put in place before decisions are made on their behalf. ${ }^{56}$

Two particular issues arise. First, it is at least possible that a desire to avoid the wrong type of mistake has contributed more to the tradition of proportionality described by the Court of Appeal in Re $T$ than has any attempt to balance autonomy and best interests. This suggests that clinicians, both in their clinical practice and in the evidence they give to courts, should place greater emphasis on the nature and source of error in any assessment of capacity. Second, mental capacity has a qualitative as well as a quantitative aspect. Different decisions make different demands on the mental capacities listed in the opening paragraph of this paper. This seems particularly to be the case where those decisions require the use of complex or emotionally salient information. ${ }^{15,39}$ This qualitative aspect of capacity may have contributed to a general acceptance that legal competence should be seen as applying only to the decision at hand. ${ }^{10,13}$ The implications for how doctors should respond as the stakes become higher remain to be elucidated.

Acknowledgments Thanks to Dr Tim Exworthy and Dr Patrick Fox.

\section{REFERENCES}

1 Re B [2002] 2 All E.R. 449

2 Adults with Incapacity (Scotland) Act 2000

3 Crichton J. Mental incapacity and consent to treatment: the Scottish experience. J Forens Psychiatry 2000;11:457-64

4 Lotman v. Security Mutual Life Insurance Company 478 F.2d. 868 (3d. Cir 1973)

5 Bouvia 225 Cal. Rptr. 297 (Cal. App. 2 Dist. 1986)

6 Cobbs v. Grant 8 Cal. 3d. 229, 242; 104 Cal. Rptr. 505; 502 P. 2d. 1 (1972)

7 Cruzan v. Director, Missouri Department of Health 497 US 261 (1990)

8 Jacobson v. Massachusetts 197 US 11 (1905)

9 Kahn v. St. Thomas Psychiatric Hospital 7 O.R. (3d.) 303 (1992)

10 Department for Constitutional Affairs. Draft Mental Incapacity Bill. London: Stationery Office, 2003

11 Scottish Executive. Adults with Incapacity (Scotland) Act 2000. Code of Practice. Edinburgh: Scottish Executive, 2002

12 Culver C, Gert B. Philosophy in Medicine. New York: Oxford University Press, 1982

13 Silberfeld M, Fish A. When the Mind Fails: a Guide to Dealing with Incompetency. Toronto: University of Toronto Press, 1994

14 Roberts L. Informed consent and the capacity for voluntarism. Am J Psychiatry 2002;159:705-12

15 Berg J, Appelbaum P, Grisso T. Constructing competence: formulating standards of legal competence to make medical decisions. Rutgers Law Rev 1996;48:345-96

16 Re MB [1997] 2 FLR 426

17 Buchanan A, Brock D. Deciding for others. Milbank Q 1986;64(suppl. 2): $17-94$

18 Marson D, Ingram K, Cody H, Harrell L. Assessing the competency of patients with Alzheimer's disease under different legal standards. Arch Neurol 1995;52:949-59

19 Wong J, Clare I, Gunn M, Holland A. Capacity to make health care decisions: its importance in clinical practice. Psychol Med 1999;29:437-46

20 Appelbaum P, Grisso T. Assessing patients' capacities to consent to treatment. N Engl J Med 1988;319:1635-8

21 National Bioethics Advisory Commission. Research Involving Persons with Mental Disorders That May Affect Decisionmaking Capacity. Rockville, MD: NBAC, 1998

$22 \operatorname{Re} T$ [1992] 4 All E.R. 649

23 Wicclair M. Patient decision-making capacity and risk. Bioethics 1991;5:91-104

24 Culver C, Gert B. The inadequacy of incompetence. Milbank $Q$ $1990 ; 68: 619-43$

25 Faden D, Beauchamp T. A History and Theory of Informed Consent. New York: Oxford University Press, 1986

26 Roth L, Meisel A, Lidz C. Tests of competency to consent to treatment. Am J Psychiatry 1977;134:279-84

27 Gaylin W. The competence of children: no longer all or none. Hastings Cent Rep 1982;12(April):33-8

28 Abernethy V. Compassion, control and decisions about competency. Am J Psychiatry 1984;141:53-8

29 Bartlett P, Sandland R. Mental Health Law: Policy and Practice. London: Blackstone, 1999

30 Glover-Thomas N. Reconstructing Mental Health Law and Policy. London: Butterworth, 2002

31 Grisso T, Appelbaum P. Assessing Competence to Consent to Treatment: a Guide for Physicians and Other Health Professionals. New York: Oxford University Press, 1998 
32 Bioethics Interest Group. Expert Panel Report to the National Institutes of Health (NIH). Research Involving Individuals with Questionable Capacity to Consent: Ethical Issues and Practical Considerations for Institutional Review Boards (IRBs). Bethesda: NIH, 1998

33 Brody H. Autonomy revisited: progress in medical ethics. J R Soc Med 1985;78:380-7

34 Eastman N, Hope R. The ethics of enforced medical treatment: the balance model. J Appl Philos 1988;5:49-59

35 Buchanan A, Brock D. Deciding for Others. The Ethics of Surrogate Decision Making. Cambridge: Cambridge University Press, 1989

36 Drane J. The many faces of competency. Hastings Center Rep 1985; 15:17-21

37 Beauchamp T. Competence. In: Cutter M, Shelp E, eds. Competency. Dordrecht: Kluwer, 1990:49-77

38 President's Commission for the Study of Ethical Problems in Medicine and Biomedical and Behavioral Research. Making Health Care Decisions, Vol. 1. Washington, DC: President's Commission, 1982

39 Beauchamp T, Childress J. Principles of Biomedical Ethics, 5th edn. New York: Oxford University Press, 2001

40 Wilks I. Asymmetrical competence. Bioethics 1999;13:154-9

41 American Psychiatric Association. Guidelines for assessing the decision-making capacities of potential research subjects with cognitive impairment. Am J Psychiatry 1998;155:1649-50

42 Winnick B. Competency to consent to treatment: the distinction between assent and objection. Houston Law Rev 1991;28:15-61

43 Terry H. Negligence. Harvard Law Rev 1915;29:40-54

44 Appelbaum P, Lidz C, Meisel A. Informed Consent. Legal Theory and Clinical Practice. New York: Oxford University Press, 1987

45 Checkland D. On risk and decisional capacity. J Med Philos 2001;26:35-39

46 Veatch R. A Theory of Medical Ethics. New York: Basic, 1981

47 White B. Competence to Consent. Washington DC: Georgetown University Press, 1994

48 Demarco J. Competence and paternalism. Bioethics 2002;16: $231-45$
49 Feinberg J. The Moral Limits of the Criminal Law: Harm to Self, Vol. 3. New York: Oxford University Press, 1986

50 Cale G. Continuing the debate over risk-related standards of competence. Bioethics 1999;13:131-48

51 Wicclair M. The continuing debate over risk-related standards of competence. Bioethics 1999;13:149-53

52 Veatch R. A Theory of Medical Ethics. New York: Basic, 1981

53 Matter of Spring 380 Mass. 629; 405 N.E. 2d. 115 (1980)

54 Matter of Quinlan 355 A.3d 647 at 664

55 R v Bournewood Community and Mental Health NHS Trust ex parte L [1998] 3 All E R 289, HL

56 Wicclair M. Patient decision-making capacity and risk. Bioethics 1991;5:91-104

57 Erde E. Breaking the shell game of consequentialism: incompetenceconcept and ethics. In: Cutter M, Shelp E, eds. Competency. Dordrecht: Kluwer, 1990:237-52

58 Checkland D. On risk and decisional capacity. J Med Philos 2001;26:35-39

59 Culver C, Gert B. The inadequacy of incompetence. Milbank $Q$ 1990;68:619-43

60 Burt R. Taking Care of Strangers. The Rule of Law in Doctor-Patient Relations. New York: Free Press, 1979

61 Stone A. The right to die: new problems for law and medicine and psychiatry. Emory Law 1988;37:627-43

62 Grisso T, Appelbaum P, Hill-Fotouchi C. The MacCAT-T: a clinical tool to assess patients' capacities to make treatment decisions. $P_{\text {sychiatr }}$ Serv 1997; 48:1415-19

63 Poythress N, Bonnie R, Monahan J, Otto R, Hoge S. Adjudicative Competence. The MacArthur Studies. Kluwer: New York, 2002

64 Grisso T. Evaluating Competencies. Forensic Assessments and Instruments, 2nd edn. New York: Kluwer, 2003

65 Appelbaum P, Grisso T. Capacities of hospitalized medically ill patients to consent to treatment. Psychosomatics 1997;38:119-25

66 R v Bournewood Community and Mental Health NHS Trust ex parte L [1998] 1 All E R 634 